\title{
HANDEBOL EM CADEIRA DE RODAS: FUNDAMENTOS DA MODALIDADE
}

Mariane Borges, Universidade Estadual de Campinas - UNICAMP, Campinas, São Paulo - Brasil

Anselmo Athayde Costa e Silva - Universidade Estadual de Campinas UNICAMP, Campinas, São Paulo - Brasil

Fernando Rosch Faria, Universidade Estadual de Campinas - UNICAMP, Campinas, São Paulo - Brasil

Priscila Samora Godoy, Universidade Estadual de Campinas - UNICAMP, Campinas, São Paulo - Brasil

Decio Roberto Calegari, Universidade Estadual de Maringá - UEM, Maringá, Paraná - Brasil

Paulo Ferreira Araújo, Universidade Estadual de Campinas - UNICAMP, Campinas, São Paulo - Brasil

José Irineu Gorla, Universidade Estadual de Campinas - UNICAMP, Campinas, São Paulo - Brasil

\section{RESUMO}

O objetivo deste estudo é identificar os conceitos básicos que contribuem para o desenvolvimento do Handebol em Cadeira de Rodas (HCR), tendo em vista a necessidade de estabelecimento de diretrizes que possam nortear os princípios do treinamento específico dessa modalidade. O texto está estruturado em três eixos: os princípios do HCR, os potenciais praticantes e o contexto de sua prática. Essas delimitações temáticas são provenientes de uma abordagem pautada na teoria da aprendizagem motora ${ }^{8}$ avançando para além dos estudos já realizados acerca de conceitos e regras, ao reunir a estes os aspectos técnico-táticos do HCR. Dessa forma, esse estudo busca contribuir para tornar claros os conhecimentos específicos que devem ser considerados pelos técnicos envolvidos com a sua pratica ao elaborar o planejamento dos treinamentos, bem como as adequações das possíveis particularidades inerentes à população envolvida.

Palavras-Chave: Deficiência física; Esporte adaptado; Treinamento.

\section{WHEELCHAIR HANDBALL: FUNDAMENTALS FROM MODALITY}

\begin{abstract}
The objective of this study is to identify the basic concepts that contribute to the development of Wheelchair Handball $(\mathrm{WCH})$, in view of the need to establish guidelines which could guide the principles of specific training of this modality. The text is divided in three areas: the principles of the $\mathrm{WCH}$, potential practioners and the context of their practice. These thematic boundaries are derived from an approach based on the theory of motor learning, ${ }^{8}$ advancing beyond the previous studies about concepts and rules to meet these technical-


tactical aspects of the $\mathrm{WCH}$. Thus, this study seeks to contribute to make clear the specific knowledge that should be considered by the technicians involved with this practice to prepare the planning of the training, as well as the adjustments of the possible peculiarities to the population involved.

Key-Words: Physical disability; Adapted sport; Training.

\section{BALONMANO EN SILLA DE RUEDAS: FUNDAMENTOS DE ESTE DEPORTE}

\section{RESUMEN}

Este estúdio tiene como objetivo identificar los conceptos básicos para el desarollo del Handball em Silla de Ruedas (HSR), considerando la necesidad de establecimento de diretrizes que puedan nortear los princípios del entrenamiento especifico de esta modalidad paradeportiva. El texto esta estruturado em três ejes: los princípios del HSR, los potenciales praticantes e el contexto de su practica. Las delimitaciones se basan en una abordagen que tiene la teoria de la aprendizaje motriz como fundamento, ${ }^{8}$ avanzando para adelante de estúdios realizados con conceptos e reglas, sumando a estos los aspectos técnico y tático del HSR. El estúdio busca construir una basis que sirva de referencia para que los entrenadores puedan considerarlas cuando organizarem sus planes y planeamentos de entrenamientos, así como los ajustes inherentes à poblacion involucrada.

Palabras-Claves: Discapacidad física; Deporte adaptado; Entrenamiento. 


\section{INTRODUÇÃO}

O Handebol em Cadeira de Rodas (HCR), uma modalidade de esporte adaptado, teve a padronização de suas regras com direcionamento específico ao cenário competitivo, no Brasil, no ano de 2005. Nesse período, Calegari, Gorla e Carminato $^{1}$ propuseram a primeira iniciativa de sistematização das regras da modalidade, com estudos que possibilitaram sua adaptação e desenvolvimento. Com isso, este esporte configurou-se como uma oportunidade a mais de prática para aquelas pessoas com deficiência física as quais possuem preferência pelo esporte coletivo e que apresentam dificuldades na participação em outras modalidades adaptadas, como o Rugby ou o Basquetebol em cadeira de rodas, devido a não preferência pessoal ou não elegibilidade nestas.

As modalidades coletivas são uma opção atrativa de prática para as pessoas com uma condição de deficiência física, seja pelo aspecto pessoal de autosuperação por meio da prática esportiva, seja pelo aspecto social por meio da interação com pessoas com as mesmas condições.

Por se tratar de uma modalidade recente em comparação com os demais esportes coletivos em cadeira de rodas, a produção de conhecimentos fundamentando a prática de HCR ainda é tímida, com a existência de estudos referentes à adaptação das regras, ${ }^{1}$ análise técnica de desempenho por scout, ${ }^{2}$ aspectos da avaliação $^{3-4}$ e adaptação e validação de testes. ${ }^{5-7}$

Por conseguinte, apesar do desenvolvimento de pesquisas como as acima citadas, lacunas ainda são encontradas limitando o desenvolvimento da modalidade. Dessa forma, idealizou-se o presente ensaio objetivando apresentar os conceitos básicos da modalidade, compreendendo desde as características individuais do atleta até aspectos técnico-táticos do jogo, de forma a proporcionar um amplo entendimento da modalidade, permitindo sua implantação por técnicos e professores de educação física. 
Para isso, o texto foi organizado de acordo com a teoria da abordagem da aprendizagem motora baseada no problema, indicada por Schmidt e Wrisberg. ${ }^{8}$ Esta abordagem consiste na realização de três considerações básicas para o planejamento adequado das sessões de prática, as quais se compõem pelas perguntas: Quem é o aprendiz? O que será ensinado? Onde o aprendiz deverá ser capaz de executar a habilidade?. ${ }^{8}$ No caso do Handebol em Cadeira de Rodas, o uso desta teoria é vantajoso uma vez que tal abordagem não apresenta modelos pré-determinados de atividades, mas permite ao profissional adequar seu planejamento de acordo com os objetivos e com as capacidades de seus atletas, as quais poderão apresentar maior diversidade m função da deficiência.

\section{ESTADO DA ARTE}

O primeiro estudo de adaptação do HCR no Brasil foi realizado em $2004^{9}$ e, consistiu em uma proposta de adaptação das regras para a prática em cadeira de rodas, contudo, neste momento, direcionando-se a uma vivência essencialmente recreativa.

Posteriormente Calegari, Gorla e Carminato, ${ }^{10}$ em 2005, realizaram um estudo exploratório não apenas identificando as iniciativas já existentes, mas também estabelecendo os parâmetros iniciais para a construção do referencial teórico e técnico do HCR, possibilitando a implantação e evolução da modalidade em sua forma competitiva.

Essa proposta esportiva delineou uma definição de duas modalidades - o HCR7, consistindo em uma adaptação do handebol de salão convencional para uma prática com sete jogadores em cadeira de rodas em quadra; e o HCR 4, sendo este a adaptação do handebol de areia para uma prática com quatro jogadores em cadeira de rodas, também em quadra. ${ }^{11}$

A partir deste momento, o HCR passou a ser praticado com foco competitivo. Competições regionais e nacionais foram organizadas no Brasil, país este que 
passou a concentrar o maior número de praticantes da modalidade, contando com 25 equipes. $^{12}$

A dupla possibilidade de prática do HCR no Brasil, tanto pelo HCR7 quanto pelo HCR4, possibilita versões dotadas de dinamismo e plasticidade. Já com relação à classificação funcional da modalidade, utiliza-se a proposta apresentada por Gatti, ${ }^{13}$ a qual observa critérios mínimos de elegibilidade e atribui 7 classes aos jogadores.

Para além do cenário nacional, em âmbito internacional, o HCR tem sido modalidade explorada em mais 11 países, sendo eles Argentina, Bolívia, Chile, Colômbia, Uruguai, Venezuela, Portugal, Austrália, ${ }^{14}$ Inglaterra, ${ }^{15}$ Áustria, Suécia ${ }^{16}$ e Japão.

\section{DESENVOLVIMENTO}

Este ensaio traz uma abordagem voltada aos aspectos técnico-táticos do HCR, os quais consistem em uma lacuna que tem limitado a ação de técnicos e professores dessa modalidade os quais, frente à escassez de conhecimento produzido até então, têm a tendência de lidar com estas questões de forma predominantemente empírica.

Para isso, segue-se abaixo, uma estruturação do estudo em três eixos principais, com discussões a respeito do aprendiz (os potenciais praticantes), a tarefa (os princípios do HCR) e o contexto-alvo (o contexto da prática de jogo do HCR).

\section{$O$ aprendiz}

Podem ser praticantes de HCR as pessoas com deficiência física as quais são impossibilitadas de participar da modalidade convencional em iguais condições de disputa com as pessoas sem deficiência ${ }^{10}$ e que se encaixem nos critérios mínimos de elegibilidade. ${ }^{13}$ 
A condição da deficiência física nos atletas praticantes dessa modalidade é oriunda, geralmente, por causas traumáticas ou congênitas. Dentre às causas traumáticas encontra-se a Lesão da Medula Espinhal (LME), ocasionada em sua maioria por acidentes automobilísticos, lesões por arma de fogo ou arma branca, mergulho em águas rasas, entre outros; e a amputação (AMP), com causa associada predominantemente aos acidentes automobilísticos e de trabalho, dentre outras. Já as lesões congênitas compreendem também LME, como a espinha bífida ou mielomeningocele. ${ }^{13}$ Também são possíveis causas as sequelas de Poliomielite (Pólio) e que compõe a categoria denominada de "Lês Autres", ou seja, aquelas sequelas causadas pelos demais tipos condições de deficiência que não se enquadram nas anteriores classificações, como a Neuropatia Periférica (doença que afeta o sistema nervoso periférico) ou má formações ${ }^{23}$.

A classificação funcional é o procedimento adotado para a busca do alcance de igualdade de condições entre os atletas durante a prática do esporte adaptado. $\mathrm{O}$ princípio dessa classificação é denominado de "Volume de Ação", a qual consiste na avaliação da movimentação residual dos jogadores para além das limitações oriundas da deficiência. ${ }^{11}$

Esse princípio também deve ser considerado pelos técnicos e professores de educação física, ao planejar a instrução e as atividades de seus jogadores. Dessa forma, a exemplificar, um jogador com uma LME à altura da $1^{\text {a }}$ vértebra torácica irá apresentar pouca estabilidade de tronco, o que pode dificultar a execução de tarefas como um passe lateral, ou alguma atividade em que seja necessária a recuperação da bola junto ao chão. Nesse caso o técnico deve orientar a atividade tendo em vista as potencialidades do jogador, de forma a minimizar erros de execução.

Cabe destacar que poderá haver casos nos quais a deficiência atinja os membros superiores, e desta forma tornar-se necessário maior atenção nas atividades que serão propostas. Isto exige que o técnico desenvolva a capacidade de efetuar a "leitura" do jogador em quadra para saber como adequar o passe à funcionalidade de cada atleta.

Conexões: revista da Faculdade de Educação Física da UNICAMP, Campinas, v. 13, n. 3, p. 195-212, jul./set. 2015. ISSN: 1983-9030 
Outro fator com relevante influência no desempenho individual é a cadeira de rodas. Segundo Yilla, ${ }^{17}$ o indivíduo e sua cadeira devem formar um sistema único em busca da utilização das capacidades remanescentes do atleta. A cadeira, dessa forma, tem potencial tanto para proporcionar maior estabilidade de melhor desempenho do jogador, quanto para prejudicar seu "volume de ação", caso esta não seja adequada.

Especificamente em relação à condição de deficiência, alguns indivíduos podem apresentar particularidades que influenciam mais incisivamente o desempenho esportivo. Exemplo disto são as pessoas com Lesões Medulares em nível mais alto da medula espinhal, as quais são suscetíveis às dificuldades de termorregulação; ${ }^{18}$ e os que utilizam hastes de metal, as quais podem dificultar ou limitar a execução de certos movimentos por parte dos atletas. Atenção similar deve ser destinada aos atletas com válvulas no crânio, como as utilizadas por algumas pessoas com hidrocefalia, conforme ressalta Sherrill, ${ }^{19}$ sendo necessário, nesse caso, a prevenção de possíveis impactos no crânio.

Essas peculiaridades das condições ou características de cada atleta devem ser consideradas pelo técnico durante todo o planejamento das atividades e prática das mesmas.

Outro fator a ser considerado acerca da iniciação da prática esportiva pelas pessoas com deficiência é a experiência prévia de cada atleta. Enquanto que indivíduos com lesões adquiridas podem ter tido experiências prévias, mesmo sem ter atuação antecedente como atletas, as pessoas com lesões congênitas podem não ter vivências anteriores com tais práticas. A existência de tal experiência pode facilitar o processo de ensino-aprendizagem, enquanto a sua ausência exigirá maior atenção durante a fase de iniciação. ${ }^{19}$

Por fim, o fator emocional do aprendiz, e sua influência na prática do esporte, devem predominar nas considerações do técnico. Como item relevante desse fator, a família possui grande proeminência uma vez que esta, segundo Dessen, ${ }^{20}$ "constitui um contexto primário de desenvolvimento, mediando o processo de Conexões: revista da Faculdade de Educação Física da UNICAMP, Campinas, v. 13, n. 3, p. 195-212, jul./set. 2015. ISSN: 1983-9030 
interação dos indivíduos com o contexto ambiental”. Os familiares possuem atuação imprescindível quanto à prática de um esporte adaptado, principalmente com atletas da fase infanto-juvenil, influenciando decisivamente $o$ desenvolvimento de aspectos relativos à motivação e também possibilitando a locomoção desses jogadores aos locais de treinamentos.

Por conseguinte, um trabalho destinado à família visando proporcionar conhecimentos sobre a prática esportiva por pessoas com deficiência, assim como sobre as capacidades de atuação de seus filhos, pode ser contribuinte, uma vez que, de acordo com Sherrill, ${ }^{21}$ não é incomum que pais fiquem preocupados com a possível rejeição social contra seus filhos com deficiência, ou até mesmos os superprotejam, preocupados com os possíveis riscos de lesão e desafios do esporte, dificultando a continuidade dos filhos na prática.

\section{A tarefa: $H C R$}

O HCR é um esporte dinâmico muito semelhante a sua versão convencional disputada por pessoas sem deficiência. Trata-se de um jogo de ataque e defesa no qual o objetivo é fazer os gols acertando uma bola entre as balizas dos adversários. A principal adaptação nessa modalidade é a redução da altura da baliza em 0,40 metros, sendo recomendada, para isso, a inserção de uma placa de metal de 3,16 metros de comprimento por 0,48 $\mathrm{m}$ de largura, na parte superior da mesma, por ganchos de metal.

Além destas adaptações, é empregado o sistema de classificação de acordo com a funcionalidade de cada um dos participantes, objetivando que as partidas possam ser praticadas em iguais condições de possibilidades. Os critérios de classificação em vigência na América do Sul atribuem a pontuação de 1,0 para o jogador mais comprometido e 4,0 para o jogador menos comprometido, com uma razão de 0,5 pontos. $^{13}$

A modalidade HCR4 é disputada no masculino e feminino e é dividida em duas categorias. No HCR4 A, a soma das classes dos jogadores em quadra não deve exceder os 12 pontos, enquanto no HCR4 B a soma deve de no máximo 7 pontos Conexões: revista da Faculdade de Educação Física da UNICAMP, Campinas, v. 13, n. 3, p. 195-212, jul./set. 2015. ISSN: 1983-9030 
e são aptos para a disputa jogadores com classe até 2,0. Já no HCR7, a soma das classes dos jogadores em quadra não deve exceder os 16 pontos.

Os fundamentos técnicos também se assemelham aos da modalidade convencional, contando com apenas algumas particularidades relacionadas à biomecânica dos movimentos em função da cadeira de rodas. Segue no Quadro 1, uma especificação dos fundamentos técnicos do jogo de HCR.

\section{Quadro 1 - Fundamentos Técnicos do HCR}

\begin{tabular}{|c|c|c|}
\hline Habilidade & Objetivo & Execução \\
\hline $\begin{array}{l}\text { Manejo de } \\
\text { Cadeira }\end{array}$ & $\begin{array}{l}\text { Permitir trocas de posições } \\
\text { rápidas e conquista das melhores } \\
\text { posições para fazer o gol. }\end{array}$ & $\begin{array}{l}\text { Aplicar força manual tocando o aro propulsor } \\
\text { com a região da palma da mão situada entre } \\
\text { os metacarpos do dedo indicador e do } \\
\text { polegar, para locomover a cadeira para trás e } \\
\text { para frente, bem como para frear e girar a } \\
\text { mesma. }\end{array}$ \\
\hline Passe & $\begin{array}{l}\text { Promover a troca da posse da } \\
\text { bola entre jogadores de uma } \\
\text { mesma equipe. }\end{array}$ & $\begin{array}{l}\text { Pode ser executado na altura do ombro com } \\
\text { uma das mãos apenas ou na altura do peito, } \\
\text { com as duas mãos. }\end{array}$ \\
\hline Recepção & $\begin{array}{l}\text { Receber a bola na troca de } \\
\text { passes entre os jogadores de } \\
\text { uma mesma equipe }\end{array}$ & $\begin{array}{l}\text { Receber a bola com as duas mãos, tendo as } \\
\text { pontas dos dedos voltadas pra fora e } \\
\text { amortecendo a bola com as palmas das mãos } \\
\text { para fazer o agarre. Pode ser realizado com } \\
\text { uma das mãos apenas. }\end{array}$ \\
\hline $\begin{array}{l}\text { Condução de } \\
\text { Bola }\end{array}$ & $\begin{array}{l}\text { Conduzir a bola por um espaço } \\
\text { da quadra }\end{array}$ & $\begin{array}{l}\text { Alternar o drible e a propulsão da cadeira } \\
\text { com ambas as mãos. Com isso, o atleta } \\
\text { desloca-se e é capaz de conduzir a bola em } \\
\text { velocidade. }\end{array}$ \\
\hline Arremesso & $\begin{array}{l}\text { Fazer o gol, arremessando a bola } \\
\text { de forma que esta adentre a } \\
\text { baliza. }\end{array}$ & $\begin{array}{l}\text { O arremesso pode ser realizado com a mesma } \\
\text { mecânica empregada no passe na altura do } \\
\text { ombro. }\end{array}$ \\
\hline Bloqueio & $\begin{array}{l}\text { Impedir a passagem do } \\
\text { adversário durante um ato de } \\
\text { marcação ou ataque. }\end{array}$ & $\begin{array}{l}\text { Posicionar a cadeira em frente ao adversário } \\
\text { para evitar a sua passagem }\end{array}$ \\
\hline
\end{tabular}

Fonte: CALEGARI (2010); COSTA; SILVA (2011).

Frente às diferentes possibilidades de combinação da equipe em quadra que ocorrem em decorrência da classificação funcional, torna-se necessário que as substituições sejam planejadas pelo técnico de forma antecipatória aos jogos. Para isso é necessário observar as características e possibilidades de cada atleta 
durante o treinamento, atribuindo-lhes funções táticas específicas. O posicionamento dentro de quadra deverá ser organizado de acordo com os tipos de habilidade dos participantes, seguindo como princípio primordial o fortalecimento do centro da defesa, no sistema tático escolhido.

Em relação à tática, no HCR7 os principais sistemas defensivos são o 6x0, 5x 1 e $3 \times 3$.

No sistema defensivo $6 \mathrm{x} 0$ os atletas permanecem posicionados entre a linha dos $6 \mathrm{~m}$ e $9 \mathrm{~m}$, contudo sem permanecerem especificamente sob a linha dos $6 \mathrm{~m}$, uma vez que isso pode impedir uma cobertura de marcação, caso necessário. Esse sistema deve ser utilizado quando a equipe adversária possui atletas com baixa estatura, ou quando seus principais arremessadores não possuem efetividade nos arremessos de longa distância utilizando, para isso, da infiltração.

Já o sistema defensivo $5 \times 1$ segue os mesmos princípios do sistema defensivo 6x0, tendo como diferença o adiantamento da marcação de um atleta adversário quando este tem maior habilidade no arremesso de longa distância, o que pode desequilibrar a partida. Esse adiantamento acontece próximo à linha dos $9 \mathrm{~m}$ ou um pouco à frente da mesma.

No sistema defensivo $3 \times 3$, os atletas organizam-se em duas "linhas" de marcação, uma na altura da linha de $7 \mathrm{~m}$ e outra próxima, ou à frente, da linha dos 9m. Este sistema deve ser utilizado quando o time adversário possui jogadores com alta estatura, ou quando contém dois ou mais arremessadores de longa distância.

Independente do sistema tático a ser empregado, ressalta-se que, no HCR4, a principal estratégia de defesa é o contra-ataque, devendo-se, portanto, atentar-se para a prevenção de pequenos erros técnicos, os quais podem tornar-se pontos adversários.

Compreende-se, por conseguinte, que o sistema defensivo deve se adequar às características individuais da sua equipe bem como às do adversário.

Conexões: revista da Faculdade de Educação Física da UNICAMP, Campinas, v. 13, n. 3, p. 195-212, jul./set. 2015. ISSN: 1983-9030 
A marcação individual só deve ser utilizada quando se tem uma equipe rápida, bem condicionada fisicamente e em situações nas quais o time adversário jogue com o goleiro fixo. Qualquer que seja o sistema defensivo, tanto no HCR7 quanto no HCR4, deve-se seguir como princípio fundamental a organização de um posicionamento que proteja o centro da quadra, permitindo ao adversário apenas o ataque pelas pontas, o que reduz o ângulo de arremesso e dificulta a sua finalização.

Em relação aos sistemas ofensivos que podem ser utilizados no HCR, Calegari et al. ${ }^{11}$ organizou variadas possibilidades a serem exploradas. Nestas, os princípios básicos para a efetividade de ataque no HCR7 são as infiltrações de pivô e os bloqueios pelas pontas. O mesmo princípio de bloqueio acompanha o HCR4, no entanto nesta modalidade a diferença positiva do ataque se dará pela maior movimentação dos jogadores.

\section{Contexto-alvo: jogo de HCR}

O contexto no qual será praticada a atividade deve ser considerado pelo técnico para que o treinamento seja o mais realista possível. O ambiente de competição, a observação dos espectadores, a pressão dos adversários, tanto psicológica quanto em vencer, são características que interferem incisivamente no desempenho dos atletas no momento competitivo.

O jogo de HCR é uma modalidade esportiva composta por um contexto de característica aberto devido à imprevisibilidade ambiental. Define-se, portanto, que contextos fechados são aqueles nos quais não há interferência do ambiente no desempenho da tarefa, ao contrário do que ocorre em contextos abertos. ${ }^{8}$

Planejar exercícios de repetição de movimentos de forma estática, sem uma conexão com a situação do contexto na qual a habilidade será requerida pode ser ineficiente, uma vez que tais desempenhos realizados em um contexto fechado de treinamento podem não se reproduzir durante um contexto aberto do jogo devido às particularidades e imprevistos presentes no cenário competitivo. 
Dessa forma, entende-se que a presença de competições no sistema de preparação dos atletas é um fator de suma importância, principalmente referente ao aspecto motivacional.

Ademais, as particularidades da preparação prévia às competições devem ser exploradas, possibilitando a mobilização do potencial funcional do organismo dos atletas, a estimulação de suas reações adaptativas, o desenvolvimento da estabilidade psicológica em relação às dificuldades do processo competitivo e o aperfeiçoamento de técnicas e táticas para aquele momento específico. ${ }^{22}$

Frente à possível falta de experiências prévias dos atletas, um trabalho para a construção de "atletas pensantes" durante o jogo competitivo pressupõe um trabalho árduo. Para isso, as estratégias deverão estar baseadas em questionamentos táticos durante os treinamentos, com a criação de situações específicas a serem solucionados pelos jogadores, exigindo um pensamento estratégico e tático constante.

Pela exploração dos aspectos táticos, as diferentes características das condições de deficiência podem ser reunidas de forma a interagirem como um conjunto durante o jogo de HCR. Para Tubino, ${ }^{23}$ a obtenção do conjunto visa fundamentalmente conseguir um perfeito entrosamento entre as qualidades possibilitando uma superação das deficiências técnicas individuais dentro de uma mesma equipe.

Para o alcance de um conjunto, as características dos atletas devem ser observadas de forma a serem exploradas segundo as potencialidades de cada jogador. Segue no Quadro 2, inicialmente, um retrato dessas características no HCR4. 
Quadro 2 - Características dos atletas por posição HCR4 (no ataque)

\begin{tabular}{|c|c|c|c|c|}
\hline & $\begin{array}{c}\text { Classe } \\
\text { Funcional }\end{array}$ & $\begin{array}{c}\text { Características } \\
\text { Físicas }\end{array}$ & & Treinamento \\
\hline $\begin{array}{c}\text { Goleiro } \\
\text { (central) }\end{array}$ & 3,0 á 4,0 & $\begin{array}{l}\text { Velocidade, força } \\
\text { agilidade }\end{array}$ & $\mathrm{e}$ & 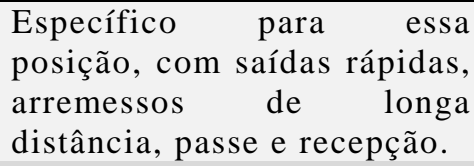 \\
\hline Armador & 1,5 a 4,0 & $\begin{array}{l}\text { Velocidade } \\
\text { agilidade }\end{array}$ & e & $\begin{array}{l}\text { Passe, recepção, arremessos } \\
\text { de médias e curtas } \\
\text { distâncias e bloqueio. }\end{array}$ \\
\hline Pivô & 1,5 á 4,0 & $\begin{array}{l}\text { Velocidade } \\
\text { agilidade. }\end{array}$ & $\mathrm{e}$ & $\begin{array}{l}\text { Passe, recepção, proteção de } \\
\text { bola e arremesso de curta } \\
\text { distância. }\end{array}$ \\
\hline
\end{tabular}

No HCR4, atletas com amputação são os mais indicados para a posição de goleiros, pois sua "lesão" permite controle total de tronco e dos membros, facilitando as defesas nas mais diversas alturas e colocações.

Atletas com LME podem desenvolver potenciais atuações na posição de pivô. $O$ atleta com lesão medular, assim como aquele com sequela de poliomielite, pode ter diminuição de força muscular de membros superiores, contudo posicionado entre as linhas de 6 e 7 metros, como nesse posicionamento, a exigência da técnica se sobressai à de força muscular, possibilitando boa atuação em seus arremessos.

Já os pontas ou armadores, no HCR4, deverão desenvolver grande mobilidade, boa "visão de jogo", possuir arremessos de qualidade tanto em curtas, como médias e longas distâncias e principalmente dominar a técnica de bloqueio, impedindo que a marcação chegue ao atleta que realizará o arremesso.

O HCR7 exige um posicionamento mais fixo em relação ao HCR4. No entanto, as características do goleiro e pivô se mantêm as mesmas, conforme pode ser visualizado no Quadro 3. 
Quadro 3- Características dos atletas por posição HCR7 (no ataque)

\begin{tabular}{|c|c|c|c|}
\hline & Classe funcional & Características físicas & $\begin{array}{l}\text { Características } \\
\text { técnicas mais } \\
\text { desenvolvidas }\end{array}$ \\
\hline Goleiro & 3,0 á 4,0 & $\begin{array}{c}\text { Força, velocidade, e } \\
\text { agilidade. }\end{array}$ & $\begin{array}{l}\text { Passe, arremesso de } \\
\text { longa distância e } \\
\text { armação de jogadas. }\end{array}$ \\
\hline Pontas & 1,0 á 3,0 & Velocidade e agilidade. & $\begin{array}{c}\text { Passe, recepção e } \\
\text { bloqueio. }\end{array}$ \\
\hline Armadores & 2,5 a 4,0 & $\begin{array}{c}\text { Força, velocidade e } \\
\text { agilidade. }\end{array}$ & $\begin{array}{c}\text { Passe, recepção, } \\
\text { bloqueio e arremessos } \\
\text { de curta, média e longa } \\
\text { distância. }\end{array}$ \\
\hline Central & 3,0 á 4,0 & $\begin{array}{l}\text { Força, velocidade e } \\
\text { agilidade. }\end{array}$ & $\begin{array}{l}\text { Passe, recepção, } \\
\text { arremessos de média e } \\
\text { longa distância. }\end{array}$ \\
\hline Pivô & 1,5 á 4,0 & Velocidade e agilidade. & $\begin{array}{c}\text { Passe, recepção e } \\
\text { arremessos de curta } \\
\text { distância. }\end{array}$ \\
\hline
\end{tabular}

Como possibilidades de exploração dessas posições, no ataque pode-se implantar dois centrais caso a defesa adversária esteja recuada, sendo o goleiro o segundo central, o qual que tem por objetivo diminuir o ritmo de jogo e realizar os arremessos dos 12 e 9m. Já os armadores devem possuir grande agilidade e raciocínio rápido, sendo os mais utilizados para armar a jogada e arremessar. Cabe aos pontas, por fim, abrir a defesa e bloquear os adversários para que não interceptem o arremesso dos armadores.

No entanto, é preciso considerar que esses posicionamentos no HCR7 podem ser modificados, conforme a organização tática adversária.

\section{CONSIDERAÇÕES FINAIS}

A padronização das regras a nível internacional deve acontecer com a realização de campeonatos internacionais e será fundamental para que o esporte possa crescer enquanto opção para pessoas com deficiência física. Fica evidente a necessidade de produção e sistematização de conhecimentos específicos para que os técnicos possam planejar e estruturar o treinamento desta modalidade com cada vez maior qualidade de prática. Conceitos básicos da modalidade foram apresentados, relacionando as características individuais dos atletas aos aspectos 
técnico-táticos do jogo, assim como estabelecendo parâmetros para a definição dos posicionamentos em quadra.

Tem-se a expectativa, nesse momento, que o presente estudo contribua no sentido de prover embasamento para a construção de uma sustentação teórica a estudos futuros, o que garantirá o crescimento da modalidade, a adesão de novos praticantes e, principalmente, a sua aplicação a diferentes faixas etárias.

\section{REFERÊNCIAS}

${ }^{1}$ CALEGARI, D. R. Adaptação do handebol para a prática em cadeira de rodas. 2010. 145 f. Tese (Doutorado em Educação Física) - Faculdade de Educação Física, Universidade Estadual de Campinas, Campinas, 2010.

${ }^{2}$ CALEGARI, D. R. et al. Performance analisys of wheelchair handball players in local competition. In: INTERNATIONAL CONVENTION ON SCIENCE, EDUCATION AND MEDICINE IN SPORT, 2008, Guangzhou, China. Proceedings... China: People's Sport, 2008. v. 1. p. 59-60.

${ }^{3}$ CARDOSO, V. D. Avaliação da composição corporal e da aptidão física relacionada ao desempenho de atletas de handebol em cadeira de rodas. 2010. 106f. Dissertação (Mestrado em Ciências do Desporto) - Faculdade de Desporto, Universidade do Porto, Porto, 2010.

${ }^{4}$ OLIVEIRA, A. C. S. Handebol adaptado: abordagem pedagógica e sua avaliação mediante a perspectiva das pessoas com deficiência física. 2011. 136f. Dissertação (Mestrado) - Universidade Federal de São Carlos, São Carlos, 2011.

${ }^{5}$ COSTA E SILVA, A. A. et al. Validating and reliability of the battery of skill tests for wheelchair handball athletes. Revista Internacional de Medicina y Ciencias de la Actividad Fisica y Del Deporte, Madrid, v. 10, p. 1-13, jul. 2014. 
${ }^{6}$ COSTA E SILVA, A. A. et al. Adaptação de uma bateria de testes para handebol em cadeira de rodas. Revista Brasileira de Ciência e Movimento, Brasília, v. 18, n. 4, p. 73 80, 2010.

${ }^{7}$ FLORES, L. J. F. et al. Potência aeróbia de praticantes de handebol em cadeira de rodas através de um teste de quadra. Caderno de Educação Física, Marechal Cândido Rondon, v. 9, n. 17, p. 75-83, $2^{\circ}$ sem. 2010.

${ }^{8}$ SCHIMIDT, R. A.; WRISBERG, C. A. Aprendizagem e performance motora: uma abordagem da aprendizagem baseada no problema. 2. ed. Porto Alegre: Artmed, 2001.

${ }^{9}$ GORGATTI, M. G.; COSTA, R. F. (Org.). Atividade física adaptada: qualidade de vida para pessoas com necessidades especiais. 2. ed. Barueri: Manole, 2008.

${ }^{10}$ CALEGARI, D. R.; GORLA, J. I.; CARMINATO, R. A. Handebol adaptado: explorando possibilidade. In: REUNIÃO ANUAL DA SOCIEDADE BRASILEIRA PARA O PROGRESSO DACIENCIA, 57., 2005, Fortaleza. Anais... Fortaleza: SBPC, 2005. p. 1-2.

${ }^{11}$ CALEGARI, D. R. et al. Regras do jogo de handebol em cadeira de rodas. In:

GORLA. J. I.; ARAÚJO P. F. (Org.). Handebol em cadeira de rodas: regras e treinamento. São Paulo: Phorte, 2010.

${ }^{12}$ ASSOCIAÇÃO BRASILEIRA DE HANDEBOL EM CADEIRA DE RODAS (ABRHACAR). Handebol em cadeira de rodas. Toledo, 2014. Disponível em: http://www.abrhacar.com.br/\#!noticias/c123r. Acesso em: 07 mar. 2014.

${ }^{13}$ GATTI, A. M. M. Classificação funcional no handebol em cadeira de rodas. 2014. 108 f. Dissertação (Mestrado em Educação Física) - Faculdade de Educação Física, Universidade Estadual de Campinas, Campinas, 2014.

${ }^{14}$ INTERNATIONAL WHEELCHAIR HANDBALL FEDERATION (IWHF). Disponível em: http://www.iwhbf.com/. Acesso em: 27 jan. 2015. 
${ }^{15}$ ENGLAND HANDBALL. Coaching: wheelchair L1. Disponível em: http://www.englandhandball.com/eha-level-1-certificate-in-coaching-wheelchair-handball/. Acesso: 10 fev. 2015.

${ }^{16}$ PARTILLE CUP. A word of handball: the week wheelchair. Disponível em: http://partillecup.com/eng/wheelchair/. Acesso em: 10 fev. 2015.

${ }^{17}$ YILLA, A. Melhora no desempenho esportivo em cadeira de rodas. In: WINNICK, J. P. Educação Física e esportes adaptados. Barueri: Manole, 2004.

${ }^{18}$ CASTRO, E. M. Atividade física adaptada. Ribeirão Preto: TECMEDD, 2005.

${ }^{19}$ SHERRILL, C. Adapted physical activity, recreation, and sport: crossdisciplinary and lifespan. 5. ed. Boston: WCB/McGraw-Hill; 1998.

${ }^{20}$ DESSEN, M. A. A família como contexto de desenvolvimento. In: FLEITH, D. S. (Org.). A construção de práticas educacionais para alunos com altas habilidades/ superdotação: o aluno e a família. Brasília: Ministério da Educação: Secretaria de Educação Especial, 2007. p. 13-27.

${ }^{21}$ SHERRILL C. Adapted physical activity, recreation, and sport: crossdisciplinary and Lifespan. 6. ed. New York: Mcgraw-Hill, 2003.

${ }^{22}$ PLATONOV, V. N. Tratado geral de treinamento desportivo. São Paulo: Phorte, 2008 .

${ }^{23}$ TUBINO, M. G. Metodologia cientifica do treinamento desportivo. 3. ed. São Paulo: Ibrasa, 1987.

${ }^{24}$ WINNICK, J. P. Educação Física e esporte adaptado. São Paulo: Manole, 2004.

Conexões: revista da Faculdade de Educação Física da UNICAMP, Campinas, v. 13, n. 3, p. 195-212, jul./set. 2015. ISSN: 1983-9030 
Recebido em: 27 jun. 2015

Aceito em: 30 ago. 2015

Contato: mariane9@yahoo.com.br 